Tropical Journal of Pharmaceutical Research February 2019; 18 (2): 295-301

ISSN: $1596-5996$ (print); 1596-9827 (electronic)

(C) Pharmacotherapy Group, Faculty of Pharmacy, University of Benin, Benin City, 300001 Nigeria.

\title{
Anti-inflammatory activity and accelerated stability studies of crude extract syrup of Cannabis sativa
}

\author{
Wilfred O Obonga ${ }^{1}$, Charles 0 Nnadi $^{1 *}$, Sunday $\mathbf{N}$ Okafor $^{1}$, Edwin 0 Omeje ${ }^{1}$, \\ Patrick Igbinnaduwa ${ }^{2}$, Charles 0 Okoli $^{3}$, Patience O Osadebe ${ }^{1}$ \\ ${ }^{1}$ Department of Pharmaceutical and Medicinal Chemistry, University of Nigeria, Nsukka 410001, Enugu State, ${ }^{2}$ Department of \\ Pharmaceutical Chemistry, University of Benin, Benin City 300001, ${ }^{3}$ Department of Pharmacology and Toxicology, University of \\ Nigeria Nsukka, 410001, Enugu State, Nigeria
}

*For correspondence: Email: charles.nnadi@unn.edu.ng; Tel: +234-8064947734

\begin{abstract}
Purpose: To formulate Cannabis sativa-based syrup and investigate its anti-inflammatory potential and the stability of the formulation under stress conditions.

Methods: The syrup was prepared using different combinations of crude $C$. sativa resin, propylene glycol, aspartame, sucrose, sodium metabisulphite (SMBs) and ethylenediaminetetraacetic acid (EDTA). The stability of the formulations was determined under accelerated temperature conditions. The anti-inflammatory activity of the resin and different formulations were evaluated by the egg albumin induced paw edema model in rats. Biochemical assay was determined by Reitman and Frankel colorimetric assay method while hematological assay was evaluated by standard protocols.

Results: EDTA-containing syrup (CE) was the most stable with estimated shelf-life of 2204 days $\left(K_{25^{\circ} \mathrm{C} \text {, }}\right.$ $4.78 \times 10^{-5} /$ day). Higher propylene glycol levels significantly improved anti-inflammatory activity compared to those containing a lower amount. All the formulations showed anti-inflammatory activity higher than the crude resin with a dose-dependent inhibition of paw edema compared with the control. There was no significant difference $(p<0.05)$ between the serum glutamate-oxaloacetate transaminase (SGOT, $13.821 \pm 0.190-16.008 \pm 1.012$ ), serum glutamate-pyruvate transaminase (SGPT, $19.241 \pm$ $1.027-22.901 \pm 1.093)$ and urea $(9.812 \pm 0.252-10.054 \pm 0.252)$ levels of the treated and $16.856 \pm$ $1.053,24.960 \pm 0.101$ and $10.654 \pm 0.925$ units/L of the control animals respectively. With the exception of eosinophil that disappeared from the blood in the third week, all the hematological parameters showed a gradual increase in lymphocytes, neutrophils, monocytes, packed cell volume (PCV), white and red blood cell counts in the third week compared to control.

Conclusion: Formulation of C. sativa as syrup using efficient carriers improves the pharmacological activity of the crude extract. SMBs and EDTA significantly enhance the stability of the syrup with no observable biochemical and hematological changes in treated animals
\end{abstract}

Keywords: Cannabis sativa, Syrup, Anti-inflammatory, Stability, Hematological

This is an Open Access article that uses a funding model which does not charge readers or their institutions for access and distributed under the terms of the Creative Commons Attribution License (http://creativecommons.org/licenses/by/4.0) and the Budapest Open Access Initiative (http://www.budapestopenaccessinitiative.org/read), which permit unrestricted use, distribution, and reproduction in any medium, provided the original work is properly credited.

Tropical Journal of Pharmaceutical Research is indexed by Science Citation Index (SciSearch), Scopus, International Pharmaceutical Abstract, Chemical Abstracts, Embase, Index Copernicus, EBSCO, African Index Medicus, JournalSeek, Journal Citation Reports/Science Edition, Directory of Open Access Journals (DOAJ), African Journal Online, Bioline International, Open-J-Gate and Pharmacy Abstracts

\section{INTRODUCTION}

Cannabis sativa remains one of the most influential strictly controlled and multi-constituent plants with multiple medicinal uses [1], yet its place in therapy has remained highly controversial [2] due to strict legislation against its use [3], controversial moral implications on its 
use [4] and increased potential for abuse [5]. Notwithstanding, there are established medical benefits attributed to the appropriate use of Cannabis and its constituents. It has been established that the seed and its oil is rich in carbohydrate, protein and essential fatty acids and these are implicated in inflammation processes and immuno-modulatory reactions.

Many researchers are of the opinion that purified Cannabis and its preparation could find their way into the armamentarium of therapeutic agents while ensuring that illegal use or abuse is completely discouraged [6]. However, to date, smoking remains one of the few ways in which Cannabis has been administered with associated low absorption and high risk of toxicity [7]. The traditional use of Cannabis for inflammatory disorders has been reported and cannabinoid (CBD) which is one of the components was found to be more effective than aspirin as an anti-inflammatory agent [8].

However, the considerable discrepancy has been reported as to the activity of CBDs in a number of animal tests for anti-inflammatory, mild analgesic and anti-pyretic activity. For instance, $\Delta^{9}$ tetrahydrocannabinol (THC) was reportedly 20 times more potent than aspirin and 2 times as potent as hydrocortisone in carrageenan edema test in rats [9] but these findings were not confirmed when $\Delta^{9}$-THC was orally administered. In fact, it was inactive in blocking carrageenaninduced edema in the rat paw model [8]. These discrepancies in anti-inflammatory activity of Cannabis, however, could be attributed in part to pharmacokinetic-related properties of Cannabis, especially the erratic absorption profile from smoking.

Experience has also shown that optimum pharmacological activity may not be resident exclusively in any of the phytoconstituents but in the bulk extract. For example, CBDs were shown to attenuate the signs and symptoms of cerebral damage in animals with autoimmune encephalomyelitis [10] while cannabichromene has also been reported to possess antiinflammatory activity [11] of less significance compared to the crude extract [8]. Against the backdrop that pharmacological (antiinflammatory) activity of Cannabis could be controlled by complex pharmacodynamic systems as well as pharmacokinetics of the extract, we formulated crude Cannabis extract syrup using different vehicles, assessed the antiinflammatory performances and its biochemical and hematological parameters in experimental animals, and also the stability of the formulations with a view to improving the anti-inflammatory activity of Cannabis extracts.

\section{EXPERIMENTAL}

\section{Materials}

The fresh $C$. sativa leaves were obtained from the Crude Drug and Research Unit of the National Drug Laws Enforcement Agency (NDLEA) Enugu Zone and identified by Mr. H. Z. Lawal, a taxonomist at the Unit. All the reagents used for this study were obtained from $\mathrm{BDH}$, England or Sigma-Aldrich, Germany and were used without further purification. The UV-VIS spectrophotometer is a U-2900 double beam UVvisible spectrophotometer wavelength range of $190-1100 \mathrm{~nm}$ with $1.5 \mathrm{~nm}$ spectral bandpass (Hitachi High-Tech Co, Japan).

\section{Preparation of crude Cannabis extract}

The dry pulverized C. sativa whole leaves (500 g) were exhaustively extracted by cold maceration in $5 \mathrm{~L}(2 \times 2.5 \mathrm{~L})$ of methanol (95\% $\mathrm{v} / \mathrm{v})$ for $48 \mathrm{~h}$. The extract was filtered, evaporated in vacuo and the dried extract stored at $0-4^{\circ} \mathrm{C}$.

\section{Preparation of Cannabis syrup}

Different batches of Cannabis extract syrup were constituted from a $100 \mathrm{mg} / \mathrm{mL}$ crude Cannabis extract (CCR), $67 \% \mathrm{w} / \mathrm{v}$ sucrose, $0.15 \% \mathrm{w} / \mathrm{v}$ aspartame, $0.1 \% \mathrm{w} / \mathrm{v}$ sodium metabisulphite (SMBs), $3.0 \% \mathrm{w} / \mathrm{v}$ EDTA and $5 \% \mathrm{v} / \mathrm{v}$ propylene glycol. All the formulations were made up to 50 $\mathrm{mL}$ in appropriate diluents as shown in Table 1 to obtain syrup strengths of 5.0 and $10.0 \mathrm{mg} / \mathrm{mL}$. The composition of the batches used for this study was optimized and selected based on solubility, stability, consistency and rheological performance of various trials of different ratios of constituents.

\section{Anti-inflammatory study}

A total of 115 adult albino rats $(100-150 \mathrm{~g})$ of either sex were divided into nine groups $(n=5)$ as follows: Group A-G received each 5, 10 and $20 \mathrm{mg} / \mathrm{kg}$ of CCR, CS-1, CS-2, CB-1, CB-2, CE-1 and CE-2 respectively. Group H received 100 $\mathrm{mg} / \mathrm{kg}$ of acetylsalicylic acid while Group I received an equivalent volume of blank formulation p.o. Inflammation was induced after I $\mathrm{h}$ of administration by injecting $0.1 \mathrm{~mL}$ undiluted fresh egg albumin into the sub planter region of the right hind paw of the rats. The paw size was measured at $0,0.5,1,2,3$, and $4 \mathrm{~h}$ intervals after egg albumin injection using digital vernier caliper $[12,13]$. 
Table 1: Composition of crude Cannabis resin syrup

\begin{tabular}{lcccccccc}
\hline Batch & $\begin{array}{c}\mathbf{C C R} \\
(\mathbf{m L})\end{array}$ & $\begin{array}{c}\text { Sucrose } \\
(\mathbf{m L})\end{array}$ & $\begin{array}{c}\text { Propylene } \\
\text { glycol }(\mathbf{m L})\end{array}$ & $\begin{array}{c}\text { Aspartame } \\
(\mathbf{m L})\end{array}$ & $\begin{array}{c}\text { Diluents } \\
(\mathbf{m L})\end{array}$ & $\begin{array}{c}\text { SMBs } \\
(\mathbf{m L})\end{array}$ & $\begin{array}{c}\text { EDTA } \\
(\mathbf{m L})\end{array}$ & $\begin{array}{c}\text { Strength } \\
(\mathbf{m g} / \mathbf{m L})\end{array}$ \\
\hline CS-1 & 2.5 & 10.0 & 5.0 & 10.0 & 22.5 & - & - & 5.0 \\
CS-2 & 5.0 & 15.0 & 2.0 & 15.0 & 13.0 & - & - & 10.0 \\
CB-1 & 2.5 & 10.0 & 5.0 & 10.0 & 20.5 & 2.0 & - & 5.0 \\
CB-2 & 5.0 & 15.0 & 2.0 & 15.0 & 9.0 & 4.0 & - & 10.0 \\
CE-1 & 2.5 & 10.0 & 5.0 & 10.0 & 15.0 & 2.0 & 5.5 & 5.0 \\
CE-2 & 5.0 & 15.0 & 2.0 & 15.0 & 5.5 & 4.0 & 3.5 & 10.0 \\
\hline
\end{tabular}

CCR $=$ crude Cannabis extract formulated at two different concentration levels $1(5 \mathrm{mg} / \mathrm{mL})$ and $2(10 \mathrm{mg} / \mathrm{mL})$ with sodium metabisulphite SMBs (CB) and//or EDTA (CE) or base formula (CS)

Edema formation was assessed in terms of the difference between the zero time linear diameter of the injected paw and its diameter at the various time intervals after egg albumin injection. For each treatment, edema level and percent inhibition of edema were calculated [14].

\section{Determination of biochemical and hematolo- gical parameters}

Animals were grouped into four $(n=5)$. Three groups received $10 \mathrm{mg} / \mathrm{kg}$ each of formulations CS-1, CB-1 and CE-1 while one group served as control. At predetermined intervals of $0,7,14$ and 21 days and prior to weekly treatment with the selected formulations, $5 \mu \mathrm{L}$ blood samples were collected from the retrobulbar plexus of the medial canthus of the eyes of each animal, pooled together group by group and centrifuged at $10000 \mathrm{x} \mathrm{g}$ for $5 \mathrm{~min}$. A $1 \mathrm{~mL}$ appropriate buffer substrate solution (DL-aspartate and $\alpha$ ketoglutarate for serum glutamate oxaloacetate transaminase, SGOT, diacetyl monoxime and thiosemicarbazide for urea and DL-alanine and a-ketoglutarate for serum glutamate pyruvate transaminase (SGPT)) and $0.20 \mathrm{~mL}$ of serum from different animal groups treated with the syrup and controls were incubated for $1 \mathrm{~h}$ at 37 ${ }^{\circ} \mathrm{C}$. The SGOT and SGPT levels were determined by Reitman and Frankel colorimetric assay method [15] using 2,4-dinitrophenylhydrazine as chromogen which forms an adduct that absorbs at $520 \mathrm{~nm}$ and urea by urease Berthelot method [16]. The other portion of the serum was used to determine the WBC (white blood cells), RBC (red blood cells), PCV (packed cell volume), eosinophils, monocyte, lymphocyte and neutrophils by standard methods [17]. In all cases, baseline hematological and biochemical measurements were carried out prior to treatment of the animals to serve as control values.

\section{Stability studies of crude extract syrup}

In order to assess the stability of the formulations, all the batches were subjected to controlled temperatures of 30,40 and $50 \stackrel{\circ}{C}$ for
90 days. At predetermined time intervals of 10 , $20,30,40,50,60,70,80$ and 90 days, the Cannabis contents were assayed spectrophotometrically and the trends of decline in concentration ascertained using zero, first and second order reaction equations. The rate constants determined were used to derive specific rate constant, $\mathrm{K}_{25^{\circ} \mathrm{C}}$ at $298 \mathrm{~K}$ using Arrhenius equation and then shelf-life ( $\left.t_{90}\right)$ of selected formulations.

\section{Statistical analysis}

The experimental results were analyzed using the Statistical Package for the Social Sciences (SPSS Inc. Chicago), v. 15.0 and GraphPad Prism v. 6.01.2012 (GraphPad Software Inc., San Diego, CA, USA) software. The antiinflammatory activities (rat paw sizes in $\mathrm{mm}$ ), biochemical parameters (SGOT, SGPT and urea in units/L) and hematological parameters (WBC in cells/ $\mu \mathrm{L}, \mathrm{RBC}$, lymphocytes, monocytes, neutrophils, eosinophil in units/ $\mu \mathrm{L}$ and PCV in \%) were expressed as a mean \pm standard deviation from the mean (SD) $(n=5)$, Student's t-test was done to test for the significant difference between the means of samples and control at $p<0.05$. In all cases, a $p<0.05$ was considered to be significant.

\section{RESULTS}

The crude Cannabis sativa resin and its various syrup formulations caused varying degrees of suppression of paw edema in rats compared to control with somewhat dose-dependent effects in most cases. However, this activity was much more evident when the Cannabis resin was formulated and delivered in syrups (Table 2 ).

The stability of syrups is important because their physicochemical properties depend on excipients employed in preparation and was assessed by determining the amount of initial concentration degraded after certain time under stressed conditions. 
Table 2: Anti-inflammatory activities of $C$. sativa resin and its formulations

\begin{tabular}{|c|c|c|c|c|c|c|c|}
\hline \multirow{2}{*}{ Group } & \multirow{2}{*}{$\begin{array}{c}\text { Dose } \\
(\mathrm{mg} / \mathrm{kg})\end{array}$} & \multicolumn{2}{|c|}{ Paw size (mm) } & \multicolumn{4}{|c|}{ Inhibition of edema (\%) } \\
\hline & & $0.5 \mathrm{~h}$ & $2 \mathrm{~h}$ & $4 \mathrm{~h}$ & $0.5 \mathrm{~h}$ & $2 \mathrm{~h}$ & 4h \\
\hline \multirow[t]{3}{*}{ A } & 5 & $0.55 \pm 0.09^{a, b}$ & $0.52 \pm 0.10^{\mathrm{a}, \mathrm{b}}$ & $0.51 \pm 0.11^{\mathrm{a}, \mathrm{b}}$ & 40.54 & 42.30 & 43.33 \\
\hline & 10 & $0.56 \pm 0.05$ & $0.50 \pm 0.09$ & $0.49 \pm 0.02$ & 40.00 & 45.05 & 45.56 \\
\hline & 20 & $0.52 \pm 0.10$ & $0.51 \pm 0.02$ & $0.49 \pm 0.08$ & 43.24 & 43.95 & 45.00 \\
\hline \multirow[t]{3}{*}{ B } & 5 & $0.42 \pm 0.11$ & $0.40 \pm 0.08$ & $0.38 \pm 0.07$ & 54.05 & 56.04 & 57.78 \\
\hline & 10 & $0.41 \pm 0.08$ & $0.39 \pm 0.06$ & $0.37 \pm 0.03$ & 55.68 & 57.14 & 58.33 \\
\hline & 20 & $0.40 \pm 0.09$ & $0.39 \pm 0.08$ & $0.36 \pm 0.07^{*}$ & 56.76 & 57.14 & 60.00 \\
\hline \multirow[t]{3}{*}{ C } & 5 & $0.46 \pm 0.10$ & $0.46 \pm 0.04$ & $0.41 \pm 0.08$ & 50.27 & 49.45 & 54.44 \\
\hline & 10 & $0.45 \pm 0.09$ & $0.41 \pm 0.12$ & $0.40 \pm 0.04$ & 51.35 & 54.95 & 55.00 \\
\hline & 20 & $0.45 \pm 0.07$ & $0.42 \pm 0.06$ & $0.40 \pm 0.06$ & 51.89 & 53.30 & 55.56 \\
\hline \multirow[t]{3}{*}{ D } & 5 & $0.32 \pm 0.09$ & $0.32 \pm 0.06$ & $0.31 \pm 0.07$ & 64.86 & 64.83 & 65.56 \\
\hline & 10 & $0.32 \pm 0.06$ & $0.31 \pm 0.00$ & $0.30 \pm 0.06$ & 64.86 & 65.38 & 66.67 \\
\hline & 20 & $0.31 \pm 0.13$ & $0.31 \pm 0.04$ & $0.30 \pm 0.04^{*}$ & 66.49 & 65.38 & 66.67 \\
\hline \multirow[t]{3}{*}{$E$} & 5 & $0.39 \pm 0.08$ & $0.38 \pm 0.07$ & $0.36 \pm 0.22$ & 57.30 & 57.69 & 60.00 \\
\hline & 10 & $0.38 \pm 0.04$ & $0.38 \pm 0.02$ & $0.37 \pm 0.06$ & 58.92 & 58.24 & 58.89 \\
\hline & 20 & $0.37 \pm 0.04$ & $0.37 \pm 0.00$ & $0.36 \pm 0.02$ & 59.50 & 58.79 & 60.00 \\
\hline \multirow[t]{3}{*}{$\mathrm{F}$} & 5 & $0.30 \pm 0.11$ & $0.30 \pm 0.08$ & $0.30 \pm 0.06^{*}$ & 67.57 & 67.03 & 66.67 \\
\hline & 10 & $0.28 \pm 0.06$ & $0.28 \pm 0.05$ & $0.28 \pm 0.03^{*}$ & 69.19 & 69.23 & 68.89 \\
\hline & 20 & $0.27 \pm 0.09$ & $0.27 \pm 0.06$ & $0.26 \pm 0.06$ & 70.81 & 70.33 & 70.55 \\
\hline \multirow[t]{3}{*}{$G$} & 5 & $0.35 \pm 0.04$ & $0.33 \pm 0.04$ & $0.30 \pm 0.01^{*}$ & 62.22 & 63.74 & 66.67 \\
\hline & 10 & $0.32 \pm 0.09$ & $0.32 \pm 0.04$ & $0.30 \pm 0.02$ & 64.86 & 64.84 & 66.67 \\
\hline & 20 & $0.31 \pm 0.07$ & $0.32 \pm 0.11$ & $0.29 \pm 0.41^{*}$ & 66.49 & 64.29 & 67.78 \\
\hline $\mathrm{H}$ & 100 & $0.26 \pm 0.10$ & $0.22 \pm 0.08$ & $0.20 \pm 0.02$ & 71.35 & 75.82 & 77.78 \\
\hline I & - & $0.92 \pm 0.04$ & $0.91 \pm 0.08$ & $0.90 \pm 0.10$ & - & - & - \\
\hline
\end{tabular}

The results of accelerated stability studies indicated that the various formulations of crude C. sativa syrup formulations may have undergone a first order kinetic degradation (Table 3). It is imperative to point out that only formulations containing equal amount (5.0 $\mathrm{mg} / \mathrm{ml}$ ) of crude Cannabis extract were used for this study, differing only in the composition of EDTA and SMBs.

The biochemical parameters are presented in Table 4. The results indicate that the SGOT,
SPGT and urea levels in the treated animal groups were not significantly $(p<0.05)$ different from the control groups within the 3 weeks of treatment.

The results of hematological parameters presented in Table 5 indicate that the indices were of similar values in all the animals treated with the formulations with fluctuations in the three weeks of administration.

Table 3: Accelerated stability of crude $C$. sativa formulations

\begin{tabular}{|c|c|c|c|c|c|c|c|c|c|}
\hline \multirow[b]{2}{*}{ Batch } & \multirow[b]{2}{*}{$\begin{array}{c}\mathrm{C}_{0} \\
(\mathrm{mg} / \mathrm{ml})\end{array}$} & \multicolumn{2}{|c|}{$30 \div \mathrm{C}$} & \multicolumn{2}{|c|}{$40^{\circ} \mathrm{C}$} & \multicolumn{2}{|c|}{$50^{\circ} \mathrm{C}$} & \multirow{2}{*}{$\begin{array}{l}\mathrm{K}_{25^{\circ} \mathrm{C}} \\
\left(\times 10^{-5}\right. \\
\text { /day) }\end{array}$} & \multirow[b]{2}{*}{$\begin{array}{l}\text { Shelf- } \\
\text { Life (day) }\end{array}$} \\
\hline & & $\begin{array}{c}C_{90} \\
(m g / m l)\end{array}$ & $\begin{array}{c}K\left(x 10^{-5}\right. \\
\text { /day) }\end{array}$ & $\begin{array}{c}C_{90} \\
(m g / m l)\end{array}$ & $\begin{array}{c}K \\
\text { (/day) }\end{array}$ & $\begin{array}{c}C_{90} \\
(m g / m l)\end{array}$ & $\begin{array}{c}K \\
\text { (/day) }\end{array}$ & & \\
\hline CS-1 & 5.0 & 2.98 & 580 & 2.56 & 0.0074 & 2.41 & 0.0081 & 522.7 & 20 \\
\hline CB-1 & 5.0 & 4.65 & 80 & 4.47 & 0.0012 & 4.28 & 0.0017 & 65.5 & 160 \\
\hline CE-1 & 5.0 & 4.96 & 0.89 & 4.85 & 0.0003 & 4.62 & 0.00088 & 4.8 & 2204 \\
\hline
\end{tabular}

$C_{0}=$ initial Cannabis concentration in the syrup, $C_{90}=$ concentration of Cannabis remaining in the syrup after 90 days, $K=$ specific first order rate constant, $K_{25^{\circ} \mathrm{C}}=$ specific rate constant at $298 \mathrm{~K}$ obtained from Arrhenius plots

Table 4: Biochemical and hematological parameters

\begin{tabular}{lccc}
\hline Treatment & SGOT (units/L) & & \\
\hline CS-1 & SGPT (units/L) & Urea (units/L) \\
CB-1 & $15.345 \pm 0.365$ & $19.241 \pm 1.027$ & $9.967 \pm 1.067$ \\
CE-1 & $16.008 \pm 1.012$ & $22.901 \pm 1.093$ & $10.054 \pm 1.081$ \\
Control & $13.821 \pm 0.190$ & $20.630 \pm 0.611$ & $9.812 \pm 0.252$ \\
\hline
\end{tabular}

Values expressed as mean $\pm S D$, $p$-values were calculated using the unpaired Student's $t$-test $(n=5) ;{ }^{*} p<0.05$ are significant; control groups were not treated. ${ }^{{ }^{a}} 1$ unit $=0.000482 \mu$ moles glutamate formed $/ \mathrm{min}$ 
Table 5: Hematological parameters in experimental animals

\begin{tabular}{|c|c|c|c|c|c|c|c|}
\hline $\begin{array}{l}\text { Time } \\
\text { (week) }\end{array}$ & $\begin{array}{c}\text { WBC } \\
(\text { cell/ } / \mu \mathrm{L})\end{array}$ & RBC (unit//LL) & $\begin{array}{l}\text { Lymphocyte } \\
\text { (unit/ } / \mu L)\end{array}$ & $\begin{array}{c}\text { Monocyte } \\
\text { (unit/ } \mu \mathrm{L} \text { ) }\end{array}$ & $\begin{array}{l}\text { Neutrophil } \\
\text { (unit/ } / \mu \mathrm{L} \text { ) }\end{array}$ & $\begin{array}{c}\text { Eosinophil } \\
\text { (unit/ } \mu \mathrm{L} \text { ) }\end{array}$ & PCV (\%) \\
\hline 0 & $9000 \pm 120$ & $(6.9 \pm 0.1) \times 10^{6}$ & $5500 \pm 31$ & $1900 \pm 14$ & $1400 \pm 23$ & $180 \pm 12$ & $46.50 \pm 2.15$ \\
\hline 1 & $10000 \pm 109$ & $(4.0 \pm 0.4) \times 10^{6}$ & $8000 \pm 28$ & $1250 \pm 28$ & $1400 \pm 21$ & $170 \pm 15$ & $41.20 \pm 1.10$ \\
\hline 2 & $9500 \pm 98$ & $(4.5 \pm 0.2) \times 10^{6}$ & $7000 \pm 80$ & $1200 \pm 21$ & $2650 \pm 54$ & $45 \pm 9$ & $39.60 \pm 0.93$ \\
\hline 3 & $15000 \pm 70$ & $(6.5 \pm 0.2) \times 10^{6}$ & $10000 \pm 98$ & $2500 \pm 34$ & $4100 \pm 45$ & 0.00 & $47.25 \pm 1.90$ \\
\hline
\end{tabular}

\section{DISCUSSION}

Cannabis extract and its various formulations caused varying degrees of dose and non-dose related suppression of paw-edema in rats. All the administered CCR doses caused an inhibitory effect much lower than that of $100 \mathrm{mg} / \mathrm{kg}$ acetylsalicylic acid. Higher propylene glycol containing formulations caused a significant $(p<$ 0.05 ) dose-dependent inhibition of paw edema.

The Cannabis syrup containing either EDTA (CE) or sodium metabisulphite (CB) did not produce an inhibitory effect different from other formulations. The potency increased in the order of magnitude $\mathrm{CE}>\mathrm{CB}>\mathrm{CS}>\mathrm{CCR}$. Various preparations of $C$. sativa have been employed for their anti-inflammatory purposes. Extracts of Cannabis have been shown to possess antiinflammatory activity [18] and $\Delta^{9}$-THC, the psychoactive component of Cannabis has also been shown to possess anti-inflammatory activity in various models [19]. In addition, cannabinol (CBN) and not cannabidiol (CBD) was shown to exhibit these activities too [20]. The improved anti-inflammatory activities of the formulations could be attributed to the effects of vehicles used and potential of syrup to overcome erratic absorption common with the traditional smoking of Cannabis.

Apart from the solubilizing effects of propylene glycol, it has been previously used to improve the bioavailability of orally administered poorly watersoluble drugs by different mechanisms [21,22]. The improved anti-inflammatory activity of the syrups over the crude extract could be partly attributed to the solubilizing power, increased polar pathway for maximum absorption and favourable partitioning of the anti-inflammatory constituent(s) of the extract by propylene glycol, and on the other hand by the increased diffusivity of cannabinoid components of C. sativa [8]. Other components of the formulations may not have improved the anti-inflammatory activity of crude Cannabis extract extensively but their usefulness in syrup formulations has been reported and validated $[23,24]$.
The stabilization effects of sodium metabisulphite and EDTA contributed to the significant improvement of the shelf lives of the syrup compared to their respective blanks. Degradation of cannabis is complex and has led to the formation of thermodynamically unstable metabolites which are difficult to separate [25]. The reactions are capricious and sensitive to certain conditions resulting in decarboxylation and isomerization reactions [25]. Thus, the stabilizers employed in these formulations could have shielded the THC or other labile components from these reactions thereby prolonging the shelf lives of simple Cannabis syrup (CS) from 20 to 160 days in CB and further 2204 days in CE.

The primary metabolic site of Cannabis and majority of the syrup components is the liver. In cases of damaged liver, SGOT and SGPT may be elevated due to leakage into the bloodstream especially when excipients are toxic enough to cause liver injury. There was no significant elevation $(p<0.05)$ of all the biochemical parameters measured. SGOT level of 13.821 16.008, SGPT $19.241-22.901$ and urea 9.812 10.054 units/L compared to $16.856,24.960$ and 10.654 units/L respectively in the control groups were recorded. The hematological erythrocytic and leucocytic indices were not significantly different in all the treated animal groups.

However, on the third week, results showed a significant increase in PCV, RBC, leucocytes, lymphocytes, monocyte and neutrophils. On the contrary, eosinophils disappeared from the blood of the treated groups in the third week. This could be attributed to the detoxification effect of eosinophils which were consumed by the combined mild toxic effect of the components of the syrup. The general increase observed for other hematological parameters within the three weeks of treatment could be attributed to the haemoconcentration induced by dehydration effect of Cannabis [26]. The effect of the formulation on the biochemical and hematological parameters supports the evidence that the components of the syrup (propylene glycol, sucrose, aspartame, SMBs, EDTA and distilled water) belonged to "generally recognized 
as safe" chemicals (GRAS) and are relatively safe for orally-targeted formulations [27].

\section{CONCLUSION}

The formulation of $C$. sativa resin as a syrup using lipophilic and hydrophilic carriers improves significantly the anti-inflammatory activity of Cannabis. Degradation of the resin in such formulations follows first order kinetic model. Furthermore, incorporation of EDTA and/or SMBs into the syrup improves its shelf-life by approximately $99 \%$. Thus, syrup is an efficient and alternative vehicle to the traditional smoking for oral delivery of $C$. sativa as an antiinflammatory.

\section{DECLARATIONS}

\section{Acknowledgement}

Dr. Wilfred Ofem Obonga thanks the Crude Drug and Research Unit of the National Drug Laws Enforcement Agency (NDLEA) Enugu, Nigeria for the gift of $C$. sativa leaves.

\section{Conflict of Interest}

No conflict of interest associated with this work.

\section{Contribution of Authors}

The authors declare that this work was done by the authors named in this article and all liabilities pertaining to claims relating to the content of this article will be borne by them.

\section{REFERENCES}

1. Razdan RK, Howes JF. Drugs related to tetrahydrocannabinol. Medicinal Res Rev 1983; 3: 119146.

2. Nadelmann EA. Progressive legalisers, progressive prohibitionist and the reduction of drug related harm. In: Health Wodak N, Nadelmann AE, O'Hare P (editors). Psychoactive drug and harm reduction: from faith to science. 1st edn. London: Whurr; 1993; pp 15-48

3. Taylor D. MPs push for biggest change in drug law for 30 years: How Cannabis is controlled across Europe. Evening Standard. 2002: 21.

4. Szasz T. The morality of drug controls. In: Hamowy $R$ (editor). Dealing with drugs: Consequences of government control. 2nd edn. Lexington: Mass; 1987; $p$ 82

5. Gordon AJ, Conley JW, Gordon JM; Conley G. Medical consequences of marijuana use: a review of current literature. Curr Psychiatry Rep (Review) 2013; 15(12): 419. doi:10.1007/s11920-013-0419-7.
6. Kabelik J, Krejei S, Santavy F. Cannabis as a medicament. Bull Narc 1960; 12: 5-6.

7. Tashkin, DP. Effects of Marijuana Smoking on the Lung. Annals of the American Thoracic Society 2013; 10(3): 239-247. doi:10.1513/AnnalsATS.201212-127FR.

8. Formukong EA, Evans AT, Evans FJ. Analgesic and antiinflammatory activity of constituents of Cannabis sativa L., Inflam 1988; 12(4): 361-371.

9. Kosersky DS, Dewey WL, Harris LS. Antipyretic, analgesic and anti-inflammatory effects of $\triangle 9-T H C$ in rats. Eur J Pharmacol 1973; 24: 1-7.

10. Wirquin I, Mechoulam R, Brewer A, Schezen E, Weidenfeld J, Brenner T. Suppression of experimental autoimmune encephalomyelitis by cannabiboids. Immunopharmacol 1994; 28: 209-214.

11. Wirth PW, Watson ES, Elsohly M, Turner CE, Murphy JC. Antiinflammatory properties of cannabichromene. Life Sci 1980; 26: 1991-1995.

12. Joseph SM, George MC, Nair JR. Effect of feeding cuttlefish liver oil on immune function, inflammatory response and platelet aggregation in rats. Current Sci 2005; 88(3): 507-510.

13. Okoli CO, Akah PA. Mechanisms of the anti-inflammatory activity of the leaf extracts of Culcasia scandens $P$. Beauv (Araceae) Pharmacol Biochem Behav 2004; 79(3): 473-481.

14. Duffy JC, Dearden JC, Rostron C. Design, synthesis and biological testing of a novel series of anti-inflammatory drugs. J Pharm Pharmacol 2001; 53: 1505-1514.

15. Susick RL, Zannoni VG. Ascorbic Acid and Elevated Dose of Ethanol SGOT Levels after an acute dose in the Guinea Pig. Alcoholism: Clin Exper Res 1987; 11(3): 265-269.

16. Weatherburn MW. Phenol-hypochlorite reaction for determination of ammonia. Anal Chem 1967; 39: 971 974.

17. Stoskopf MK, Neeley E, Mangold B. Avian hematology in clinical practice: Part 1. Modern Veterinary Practice 1981; 64: 629-632.

18. Dewey WL, Harris LS, Kennedy JS. Some pharmacological and toxicological effects of 1-transdelta-8- and 1-trans-delta-9-THC in laboratory rodents. Arch Int Pharmacodyn 1972; 196: 133-145.

19. Sander J, Jackson DM, Starmer GA. Interactions among the cannabinoids in the antagonism of abdominal constriction response in the mouse. Psychopharmacol 1979; 61: 281-285.

20. White HL, Tansik RL. Effects of delta-9-THC and cannabinol on phospholipase and other enzyme regulating arachidonate metabolism. Prostaglandins Med 1980; 4: 409-411.

21. Gao P, Guyton ME, Huang T, Bauer JM, Stefanski KJ, Lu $Q$. Enhanced oral bioavailability of a poorly water soluble drug PNU-91325 by supersaturatable formulations. Drug Dev Ind Pharm 2004; 30(2): 221-229.

22. Maheshwari RK, Rajagopalan $R$. Formulation and evaluation of paracetamol syrup made by mixed 
Obonga et al

solvency concept. Der Pharmacia Lettre 2012; 4(1): 170-174.

23. Adopoju TS, Olasehinde EF, Aderibigbe AD. Effect of Sodium Metabisulphite and Disodium Ethylenediaminetetraacetic acid (EDTA) on the Stability of Ascorbic Acid in Vitamin C Syrup. Researcher 2014; 6(10): 6-9.

24. Sateesha SB, Rajamma AJ, Shekar AS, Mohamed Mutahar RK, Jayanthi A. Formulation and stability study of palatable norfloxacin dry syrup: comparison among different preparation methods. Asian J Pharm Sci 2010; 5(5): 175-184.
25. Barnett G, Chiang CN, Perez-Reyes M, Owens SM. Kinetic study of marijuana. J Pharmacokin Biopharm 1982; 10: 495-506.

26. Stephens JS, Roffman RA, Simpson EE. Adult marijuana users seeking treatment. J Consult Clin Psychol 1993; 188: 1100-1104.

27. Toxicological information on propylene glycol. Compiled on the Hazardous Substance Data Bank (HSDB). National Library of Medicine. Bethesda, Md. http://toxnet.n/m.nih.gov/cgibin/sis/htmlgen?HSDB. 